It follows from all this that the British Glaciological Society, which had the wisdom and enterprise to launch the new fournal of Glaciology, thereby has provided an effective organ for mutual information and interchange of thought to scientists working in a number of interrelated and interdependent fields of research - glaciology, meteorology, climatology, physical geography, geology, pedology, hydrology, oceanography, archaeology, ecology and palaeontology. 'That being true, there is every reason to believe that the fournal of Glaciology is starting upon a highly useful and successful career.

\title{
THE SOCIETY AND THE JOURNAL
}

As a result of the advent of the Fournal of Glaciology and a certain amount of publicity the Society has grown considerably. In November the number of members was 128 ; members and subscribers to the Journal now total about 360 . It is not our purpose to rest at this figure. The size and scope of the Journal depend upon the size of its circulation, from which it follows that this must be further increased. Members will help the Society and increase its usefulness to themselves by making its existence known to any of their friends and colleagues who are likely to be genuinely interested in its work. Particulars and a prospectus will be found on the last page of this issue.

The reception given to the first number of the fournal of Glaciology has been gratifying. Several dozens of letters have been received and it is clear that it fills a real want. Appreciations have been sent from Switzerland, the United States of America, Canada, Sweden, Norway, France, Belgium, Poland, Czechoslovakia, Eire and several other countries.

It is satisfactory to the Committee and to the Editorial Committee that the Fournal of Glaciology has been launched and appreciated.

\section{GLACIER RESEARCH}

\section{THE GLACIER PHYSICS COMMITTEE}

GLACIOLOGY has now reached a stage when mere observation in the field is no longer an adequate method of attack for the problems which are still unsolved. Experimental research on the fundamental physical and mechanical properties of ice is urgently required before a quantitative theory of glacier flow, based upon modern concepts of plasticity in crystalline solids, can be formulated. For testing such theories in the field, novel methods of research will be needed for measuring flow rates and stresses in the interior of glaciers at considerable depths.

It is clear that the development of research on lines such as these will only be possible with the co-operation of experts in several fields. With this purpose in view a Glacier Physics Committee has been formed on the initiative of Dr. M. F. Perutz and under the chairmanship of Mr. G. Seligman. The following have agreed to serve on it:

Dr. F. P. Bowden (Friction of solids).

Dr. E. C. Bullard, F.R.S. (Geophysics).

Mr. Vaughan Lewis (Geomorphology). 